OPEN ACCESS

Edited by:

Mas Rizky A. A. Syamsunarno, Padjadjaran University, Indonesia

Reviewed by: Ali H. Eid,

Qatar University, Qatar

Carlos R. Pungitore,

Consejo Nacional de Investigaciones Científicas y Técnicas (CONICET),

Argentina

${ }^{*}$ Correspondence:

Kyungho Kim

jk6012@kiom.re.kr

Specialty section:

This article was submitted to

Ethnopharmacology,

a section of the journal

Frontiers in Pharmacology

Received: 26 March 2021

Accepted: 11 June 2021

Published: 02 July 2021

Citation:

Kim TI, Kim Y-J and Kim K (2021)

Extract of Seaweed Codium fragile

Inhibits Integrin allb $\beta 3$-Induced

Outside-in Signaling and

Arterial Thrombosis.

Front. Pharmacol. 12:685948.

doi: $10.3389 /$ fphar.2021.685948

\section{Extract of Seaweed Codium fragile Inhibits Integrin allb 33 -Induced Outside-in Signaling and Arterial Thrombosis}

\author{
Tae In Kim, Yeon-Ji Kim and Kyungho Kim* \\ Korean Medicine-Application Center, Korea Institute of Oriental Medicine, Daegu, South Korea
}

Seaweeds are thought to be promising candidates for functional foods and to help prevent thrombotic and related cardiovascular diseases. Codium fragile (Suringer) Hariot has been traditionally used as a culinary ingredient, and it possesses a range of biological activities, including the inhibition of platelet function. However, the mechanism of this inhibition is unclear. The aim of this study was to examine the inhibitory effect of $C$. fragile in platelet function. The antiplatelet activity of $C$. fragile on agonist-activated platelet aggregation, granule secretion, calcium mobilization, platelet spreading, and clot retraction was assessed. The phosphorylation of c-Src, Syk, PLC $\gamma 2$, and several proteins involving in the allb $\beta 3$ integrin outside-in signaling pathway were also studied in thrombin and CRP-stimulated platelets. The antithrombotic effect was investigated in mice using ferric chloride-induced arterial thrombus formation in vivo. Transection tail bleeding time was used to evaluate whether $C$. fragile inhibited primary hemostasis. The main components and contents of $C$. fragile ethanol extract were confirmed by GC-MS analysis. C. fragile significantly impaired agonist-induced platelet aggregation granule secretion, calcium mobilization, platelet spreading, and clot retraction. Biochemical analysis revealed that $C$. fragile inhibited the agonist-induced activation of c-Src, Syk, and PLC $\gamma 2$, as well as the phosphorylation of PI3K, AKT, and mitogen-activated protein kinases (MAPKs). The inhibitory effect of $C$. fragile resulted from an inhibition of platelet allb $\beta 3$ integrin outside-in signal transduction during cell activation. Oral administration of $\mathrm{C}$. fragile efficiently blocked $\mathrm{FeCl}_{3}$-induced arterial thrombus formation in vivo without prolonging bleeding time. GC-MS analysis revealed that phytol was the main constituent and the total content of isomers was $160.8 \mathrm{mg} / \mathrm{kg}$. Our results demonstrated that $C$. fragile suppresses not only the inside-out

\footnotetext{
Abbreviations: ACD, acid-citrate-dextrose solution; ADP, adenosine diphosphate; ATP, adenosine triphosphate; AKT, protein kinase B; ASA, acetylsalicylic acid; BW, body weight; c-Src, sarcoma tyrosine-protein kinase; CMC, carboxymethylcellulose; CRP, collagen-related peptide; DMSO, dimethyl sulfoxide; EGTA, ethylene glycol-bis( $\beta$-aminoethyl ether)-N, $N, \mathrm{~N}^{\prime}, \mathrm{N}^{\prime}$ tetraacetic acid; ERK, extracellular signal-regulated kinase; FAK, focal adhesion kinase; $\mathrm{FeCl}$, ferric chloride; FG, fibrinogen: GC-MS, gas chromatography-mass spectrometry; MAPK, mitogen-activated protein kinase; PI3K, phosphoinositide 3-kinase; PLC $\gamma 2$, phospholipase C $\gamma 2$; PRP, platelet-rich plasma; PPACK, d-Phe-Pro-Arg-chloromethyl ketone; RT, room temperature; SLP-76, SH2 domain-containing leukocyte protein of 76 kDa; Syk, spleen tyrosine kinase; Vav1, Proto-oncogene vav; U46619, thromboxane A2 analogue
} 
signaling of allb $\beta 3$ integrin but also outside-in signal transmission. Therefore, $C$. fragile could be an effective antiplatelet therapeutic candidate.

Keywords: platelet, thrombosis, outside-in signaling, integrin allb $\beta 3$, codium fragile

\section{INTRODUCTION}

Platelets play crucial roles in thrombosis and hemostasis. Platelet integrin $\alpha \operatorname{IIb} \beta 3$ is a key mediator of platelet aggregation and is abundantly expressed on the platelet surface (Shen et al., 2013). In resting platelets, integrin $\alpha \operatorname{IIb} \beta 3$ is maintained in a low-affinity binding state, in which the extracellular domain of $\alpha \operatorname{Ilb} \beta 3$ integrin is in a closed conformation. However, upon the activation of a platelet, $\alpha \mathrm{IIb} \beta 3$ undergoes a conformational change from a low-affinity state to a high-affinity ligand-binding state, in which it can bind ligands such as fibrinogen (FG) and von Willebrand factor (Takagi et al., 2002; Bennett, 2005; Li et al., 2010). Ligand binding to activated integrin $\alpha \mathrm{IIb} \beta 3$ induces a cascade of outside-in signaling events, thereby facilitating platelet spreading, aggregation, clot retraction, and thrombosis (Takagi et al., 2002; Gong et al., 2010).

Outside-in signaling via platelet integrin $\alpha \mathrm{IIb} \beta 3$ involves a wide range of enzymes, signaling adaptors, and cytoskeletal components (Estevez et al., 2015). The integrin $\alpha \mathrm{IIb} \beta 3$-induced platelet outsidein signaling pathway is initiated by members of the sarcoma tyrosine-protein kinase (c-Src) family of kinases (SFKs)mediated phosphorylation events. Cellular and $\mathrm{c}-\mathrm{Src}$ is associated with the cytoplasmic tail of $\beta 3$ integrin and activated by the signaling cascades involved in the recruitment and activation of focal adhesion kinase (FAK), phosphoinositide 3kinase (PI3K), and protein kinase B (AKT) (Arias-Salgado et al., 2003; Li et al., 2010; Durrant et al., 2017). Ligand binding to integrin $\alpha \operatorname{IIb} \beta 3$ also triggers the tyrosine phosphorylation of signaling cascades involved in the recruitment and activation of spleen tyrosine kinase (Syk), phospholipase $\mathrm{C} \gamma 2$ (PLC $\gamma 2)$, and $\mathrm{SH} 2$ domain-containing leukocyte protein of $76 \mathrm{kDa}$ (SLP-76), the proto-oncogene vav (Vav1), PI3K, and more, thereby initiating downstream platelet responses, such as granule secretion, platelet spreading, and clot retraction (Law et al., 1999; Phillips et al., 2001; Wonerow et al., 2003; Suzuki-Inoue et al., 2007b).

The ligand-binding function of integrin $\alpha \operatorname{IIb} \beta 3$ has been considered as a potential target for the development of antithrombotic agents (Estevez et al., 2015; Xu et al., 2016). However, current antithrombotic agents have significant side effects against thrombocytopenia and increase the risk of bleeding (Alexander and Peterson, 2010). These side effects limit the applicability and dosage of the antithrombotic agents, thereby restricting their effectiveness (Wang et al., 2014b; Xu et al., 2016). Recently, studies have suggested that selectively targeting the integrin $\alpha \mathrm{IIb} \beta 3$-induced platelet outside-in signaling pathway allows for strong inhibition of thrombosis without hemostasis (Estevez et al., 2015). The main advantage of targeting $\alpha \mathrm{IIb} \beta 3$ integrin-mediated platelet outside-in signaling is that intervention in this pathway does not affect primary platelet adhesion and aggregation, which are important for hemostasis, but limits the size of thrombus formation, which prevents vascular occlusion (Estevez et al., 2015). Thus, selective inhibitors of integrin outside-in signaling could be potential new antithrombotic drugs.

Cardiovascular disease (CVD) is the leading cause of global mortality and morbidity. There are several risk factors associated with CVD, including high cholesterol, diet, hypertension, atherosclerosis, and thrombosis (Falk, 2006; Saleh Al-Shehabi et al., 2016). The healing properties of natural products have long been identified as one of the most important strategies for treating and managing CVD (Al Disi et al., 2015; Shaito et al., 2020). Recently, the interest in natural products including medicinal herbs has been increased based on the effectiveness against CVD (Shaito et al., 2020). Due to the wide range of biological activities, natural products offer a promise to develop novel pharmacological agents that may prove promising in controlling CVD. Edible marine algae are considered to be good sources of nutrients, and the algae have diverse biological activities, including anti-inflammatory, antioxidative, anti-cancer, and anti-nociceptive effects (Wang et al., 2014a). Codium fragile (Suringer) Hariot is a heavily utilized edible green alga belonging to the family Codiaceae. The algae are widely distributed along the coasts of East Asia, Oceania, and Northern Europe. In Korea, $C$. fragile has been used as a culinary ingredient and traditional medicine to treat enterobiasis, dropsy, and dysuria (Lehnhardt Pires et al., 2013). Several studies have indicated a protective effect of $C$. fragile against pro-inflammatory stimuli, oxidative damage, and tumor progression in experimental models (Kang et al., 2012; Lee et al., 2013; Dilshara et al., 2016). Sterol-based compounds with varying bioactivities were identified as the main components of $C$. fragile extract (Rubinstein and John Goad, 1974; Lee et al., 2013). However, the protective effect and molecular mechanisms underlying the potential inhibitory effects of C. fragile on platelet thrombus formation have not been fully elucidated. Therefore, in the present study, we aimed to clarify whether $C$. fragile is involved in the attenuation of platelet function and integrin $\alpha \mathrm{IIb} \beta 3$ signaling and to identify which compounds produce antiplatelet activity in $C$. fragile.

In the present study, we found that extract of $C$. fragile inhibited thrombus formation in vivo and in vitro. C. fragile specifically inhibited platelet activation and aggregation induced by thrombin, collagen, collagen-related peptide (CRP), adenosine diphosphate (ADP), and U46619 (thromboxane A2 analogue). Using biochemical approaches, we found that the phosphorylation levels of the c-Src/Syk/PLC $\gamma 2 / \mathrm{PI} 3 \mathrm{~K} / \mathrm{AKT} /$ MAPK axis were inhibited by treatment with C. fragile. GCMS analysis was conducted to identify and quantify the main constituents of $C$. fragile extract. C. fragile inhibited platelet spreading on immobilized FG and clot retraction. These findings suggest that $C$. fragile regulates integrin $\alpha \mathrm{IIb} \beta 3$ mediated outside-in signaling by the inhibition of platelet activation. Studies using a mouse model of $\mathrm{FeCl}_{3}$-induced arterial thrombosis indicated that $C$. fragile plays a crucial role in arterial thrombosis. The tail bleeding time was not significantly 
higher in C. fragile-treated mice than in control mice. These results demonstrate that $C$. fragile can potentially exert antiplatelet and antithrombotic effects without affecting hemostasis.

\section{MATERIALS AND METHODS}

Reagents. Human thrombin, PGE1, rhodamine-phalloidin, dimethyl sulfoxide (DMSO), ADP, fibrinogen, human fibrinogen, ferric chloride $\left(\mathrm{FeCl}_{3}\right)$, Acetylsalicylic acid (ASA), and all the reagents were purchased from Sigma (St. Louis, MO, United States). Equine tendon collagen (type I) and ATP luciferin/luciferase reagent were obtained from Chrono-log (Havertown, PA). D-Phe-Pro-Argchloromethyl ketone (PPACK) was purchased from EMD Millipore (Billerica, MA, United States). CRP was obtained from Dr Richard Farndale (Department of Biochemistry, University of Cambridge, United Kingdom). Phycoerythrin (PE)-conjugated isotype control IgGs, rat monoclonal antibodies against mouse P-selectin, activated $\alpha \mathrm{IIb} \beta 3$ (JON/A) were from Emfret Analytics (Eibelstadt, Germany). Antibodies against phospho-c-Src at Tyr416, phospho-Syk at Tyr525/526, phospho-PLC $\gamma 2$ at Tyr759, phosphoPLC 22 at Tyr1217, phospho-PI3K p85a/ $\beta$ at Tyr458/p55a/ $\gamma$ at Tyr199, phospho-Akt at Ser473, phospho-p38 at Thr180/Tyr182, phospho-ERK at Thr202/Tyr204, phosphor-FAK at Tyr397, Total c-Src, Total Syk, Total PLC $\gamma 2$, Total PI3K p85, Total Akt, Total p38, Total ERK, Total FAK, and actin were obtained from Cell Signaling (Danvers, MA, United States). Monoclonal antibodies against phospho-integrin $\beta 3$ at Tyr 759 and Total integrin $\beta 3$ were obtained from Santa Cruz (Santa Cruz, CA, United States). Calcium dye (FLIPR Calcium Assay kit) was from Molecular Devices (Sunnyvale, CA, United States). Phytol (a mixture of isomers) was purchased from Sigma (St. Louis, MO, United States). HPLC-grade methanol was obtained from JT Baker (Philipsburg, NJ, United States).

C. fragile preparation. The $C$. fragile was collected from the Wando Island coast of Korea, and its identity was confirmed by Dr Wei Li. A voucher specimen (KIOM-30) was deposited at the Herbarium of Korean Medicine-Application Center, Korea Institute of Oriental Medicine, Republic of Korea. The collected C. fragile was soaked in fresh water for a day to remove salt and dry at $65^{\circ} \mathrm{C}$. The dried $C$. fragile $(50.0 \mathrm{~g})$ was pulverized and extracted with $1 \mathrm{~L}$ of $70 \% \mathrm{EtOH}$ or $1 \mathrm{~L}$ of water at room temperature for 2 weeks. The filtrate was evaporated and freeze-dried (22.86 g, yield $45.7 \%$ ) and the dry extract powder was stored at $4^{\circ} \mathrm{C}$ until used (Supplementary Figure S1A).

Instrumentation. The GC-MS analysis was conducted using the Shimadzu GC-MS-QP2010 Ultra system (GC-Gas Chromatograph GC-2010 Plus, Injector-AOC-20i, Autosampler-AOC-20s). Data acquisition and processing was used (GC-MS Real-Time Analysis).

Preparation of Standard and Sample Solutions. The C. fragile ethanol extract was dissolved in methanol (HPLC grade) using an ultrasonicator (JAC Ultrasonic JAC-3010) at $6 \mathrm{mg} / \mathrm{ml}$ concentration. After extraction, the solution was filtered with $0.2 \mu \mathrm{m}$ membrane and the fraction of $1 \mu \mathrm{L}$ filtrate was analyzed using GC-MS system. A standard curve of the phytol solution was prepared at $1 \mathrm{mg} / \mathrm{ml}(1,000 \mathrm{ppm})$ with methanol.
GC-MS analysis condition. GC-MS analysis was performed to identify of contents of phytol in C. fragile. GC-MS analysis was conducted using DB-5 column $(30 \mathrm{~mm} \times 0.25 \mathrm{~mm} \times 0.25 \mu \mathrm{m})$. The carrier gas used helium gas (99.999\%) eluted with a flow rate of $0.78 \mathrm{ml} / \mathrm{min}$ and the split ratio was $1: 20$. The injector temperature was set at $250^{\circ} \mathrm{C}$, column oven programmed from $110^{\circ} \mathrm{C}$ (isothermal for $2 \mathrm{~min}$ ), with an increasing rate of $10^{\circ} \mathrm{C} / \mathrm{min}$ to $200^{\circ} \mathrm{C}$, then $5^{\circ} \mathrm{C} / \mathrm{min}$ to $280^{\circ} \mathrm{C}$, finishing with a $9 \mathrm{~min}$ isothermal at $280^{\circ} \mathrm{C}$. Ion source electron voltage with $70 \mathrm{eV}$ and Ion source temperature was set was $280^{\circ} \mathrm{C}$. Calibration curves, established by standard solution diluted with solvent at each concentration and the limits of detection (LOD) and quantification (LOQ) under the chromatographic conditions, were determined by injecting a series of standard solutions. Chromatograms of each sample were collected under the same condition.

Mice. Wild-type (WT, C57BL/6 strain, 6-8 weeks old, 18-22 g, BW) male mice were obtained from DooYeol Biotech (Seoul, Korea) and acclimated for 1 week. The WT mice were then divided randomly into four groups of five to ten animals each: 1) vehicle group (orally administrated $0.5 \%$ low-viscosity CMC), 2) low dose of $C$. fragile treated group $(50 \mathrm{mg} / \mathrm{kg}, \mathrm{BW}), 3)$ high dose of C. fragile treated group $(100 \mathrm{mg} / \mathrm{kg}, \mathrm{BW})$, and 4) ASA treated group $(100 \mathrm{mg} / \mathrm{kg}, \mathrm{BW})$. The mice were housed in a conventional animal facility with free access to food and water in a controlled temperature and humidity environment under a 12$\mathrm{h} / 12$ - $\mathrm{h}$ light/dark schedule. The animals were cared for in accordance with the dictates of the National Animal Welfare Law of Korea. The animal experiments (reference number \#D20-057) were approved by the Animal Care and Use Committee of the Korea Institute of Oriental Medicine (KIOM, Daegu, Korea) and performed in accordance with their guidelines.

Isolation of mouse blood platelets. Mouse blood was drawn from isoflurane-anesthetized WT (6-8 weeks old) mice from the inferior vena cava using a one-ninth volume of citrate-dextrose solution (ACD, Sigma). Mouse whole blood was centrifuged at $300 \mathrm{~g}$ for $20 \mathrm{~min}$ at room temperature (RT) to obtain platelet-rich plasma (PRP). The mouse and human PRP were collected and recentrifuged at $700 \mathrm{~g}$ for $4 \mathrm{~min}$ in the presence of $0.5 \mu \mathrm{M}$ PGE1. The platelet pellet was suspended in HEPES-Tyrode's buffer containing $10 \% \mathrm{ACD}$ and centrifuged at $700 \mathrm{~g}$ for $5 \mathrm{~min}$. The pellet was re-suspended in HEPES-Tyrode's buffer, and the final suspensions were adjusted to $3 \times 10^{8}$ platelets $/ \mathrm{ml}$.

Platelet aggregation and ATP secretion. The platelet aggregation assay was performed as previously described (Kim et al., 2018). Washed platelets were pre-incubated with $0.01 \%$ DMSO or various concentrations of $C$. fragile $(30,50$, and $100 \mu \mathrm{g} /$ $\mathrm{ml})$ or ASA $(30,50$, and $100 \mu \mathrm{M})$ for $10 \mathrm{~min}$ at $37^{\circ} \mathrm{C}$ and then stimulated with numerous agonists. Platelet aggregation was measured in a 4-channel platelet lumi-aggregometer (Chronolog Corp, Havertown, and PA) at $37^{\circ} \mathrm{C}$ with stirring at $1,000 \mathrm{rpm}$. Platelet secretion was monitored as $\mathrm{ADP} / \mathrm{ATP}$ release by addition of luciferin/luciferase reagent (Chrono-log) to the platelet suspension. In some experiments, mouse platelets were incubated with $C$. fragile $(100 \mu \mathrm{g} / \mathrm{ml})$ prior to treatment with $2 \mathrm{mM}$ EGTA for $10 \mathrm{~min}$ at $37^{\circ} \mathrm{C}$. In some experiments, mouse platelets were incubated with $100 \mu \mathrm{g} / \mathrm{ml}$ of $C$. fragile aqueous 
extract for $10 \mathrm{~min}$ at $37^{\circ} \mathrm{C}$ and then stimulated with $0.025 \mathrm{U} / \mathrm{ml}$ thrombin or $2 \mu \mathrm{g} / \mathrm{ml}$ Collagen.

$\mathrm{TxB}_{2}$ generation assay. Washed platelets were pre-incubated with $0.01 \%$ DMSO or various concentrations of $C$. fragile $(30,50$, and $100 \mu \mathrm{g} / \mathrm{ml})$ or ASA $(100 \mu \mathrm{M})$ for $10 \mathrm{~min}$ at $37^{\circ} \mathrm{C}$ and then stimulated with thrombin $(0.025 \mathrm{U} / \mathrm{ml})$ or CRP $(0.2 \mu \mathrm{g} / \mathrm{ml})$ in an aggregometer at $37^{\circ} \mathrm{C}$ with stirring $(1,000 \mathrm{rpm})$. The reaction was stopped after $5 \mathrm{~min}$ by the addition of $2 \mathrm{mM}$ EGTA containing $0.1 \mathrm{M} \mathrm{KCl}$ and $5 \mathrm{mM}$ indomethacin for $10 \mathrm{~min}$ on ice. The mixture was then centrifuged at $6,000 \mathrm{~g}$ for $3 \mathrm{~min}$, and the supernatant was stored at $-80^{\circ} \mathrm{C}$ until analysis. Thromboxane $\mathrm{B}_{2} \quad\left(\mathrm{TxB}_{2}\right)$ levels were measured using an enzyme-linked immunosorbent assay kit (Enzo Life Sciences, Farmingdale, NY) according to the manufacturer's protocol.

Flow cytometric analysis. Washed platelets were preincubated with $0.01 \%$ DMSO or various concentrations of $C$. fragile $(30,50$, and $100 \mu \mathrm{g} / \mathrm{ml})$ for $10 \mathrm{~min}$ at $37^{\circ} \mathrm{C}$. Platelets were treated with thrombin $(0.025 \mathrm{U} / \mathrm{ml})$ or CRP $(0.2 \mu \mathrm{g} / \mathrm{ml})$ for $5 \mathrm{~min}$ at $37^{\circ} \mathrm{C}$, followed by incubation with PE-conjugated antibodies against $\mathrm{P}$-selectin or activated $\alpha \mathrm{IIb} \beta 3$ integrin (JON/A) for $15 \mathrm{~min}$. Cells were analyzed by flow cytometry (Gallios, Beckman Coulter).

$\mathrm{Ca}^{2+}$ mobilization. $\mathrm{Ca}^{2+}$ mobilization was measured as previously described (Kim et al., 2018). Platelets $\left(1 \times 10^{8} / \mathrm{ml}\right)$ were suspended in HEPES-Tyrode's buffer, $\mathrm{pH} 7.4$ without $\mathrm{CaCl}_{2}$ and treated with $0.01 \%$ DMSO or C. fragile $(30,50$, and $100 \mu \mathrm{g} /$ $\mathrm{ml})$ or ASA $(100 \mu \mathrm{M})$ for $10 \mathrm{~min}$ at $37^{\circ} \mathrm{C}$. Cells were incubated with a $\mathrm{Ca}^{2+}$ dye (FLIPR Calcium five Assay kit) for $30 \mathrm{~min}$ at $37^{\circ} \mathrm{C}$ in the dark, followed by stimulation with thrombin $(0.025 \mathrm{U} / \mathrm{ml})$ or CRP $(0.2 \mu \mathrm{g} / \mathrm{ml})$. Cytosolic $\mathrm{Ca}^{2+}$ levels were measured using a spectrofluorometer (Spectramax I3, Molecular Devices) with an excitation wavelength of $485 \mathrm{~nm}$ and an emission wavelength of $525 \mathrm{~nm} \mathrm{Ca}^{2+}$ mobilization was quantified by area under the curve (AUC) and expressed in relative fluorescence units.

Platelet spreading assay. Glass coverslips were coated with human fibrinogen (FG), $100 \mu \mathrm{g} / \mathrm{ml}$, for $1 \mathrm{~h}$ at $37^{\circ} \mathrm{C}$ and then postcoated with $1 \%$ fatty acid-free BSA for $1 \mathrm{~h}$ at RT. Mouse platelets, $400 \mu \mathrm{L}\left(2 \times 10^{7} / \mathrm{ml}\right)$, were incubated on the coverslip for $2 \mathrm{~h}$ at $37^{\circ} \mathrm{C}$ in the presence of $0.025 \mathrm{U} / \mathrm{ml}$ thrombin. After washing, adherent and spread platelets were fixed with $3 \%$ paraformaldehyde, permeabilized with $0.1 \%$ Triton X-100, blocked with $0.1 \%$ BSA, and stained with $0.1 \mu \mathrm{g} / \mathrm{ml}$ rhodamine-conjugated phalloidin (Sigma). Images were obtained using an Olympus microscope (IX73, Seocho, Seoul, Korea) equipped with $100 \mathrm{x} / 1.3 \mathrm{NA}$ oil objective lens and recorded with a camera (Andor Zyla sCMOS). Care was taken to image a given fluorochrome at the same settings for all experimental permutations using MetaVue (version 7.8.3.0). Adherent and spreading platelets were monitored in an area of $0.006 \mathrm{~mm}^{2}$ and counted in 10 separate fields. The surface area of spread platelets was measured as pixels using ImageJ (v1.52a).

Immunoblotting. Washed platelets were stimulated with thrombin $(0.025 \mathrm{U} / \mathrm{ml})$ or CRP $(0.2 \mu \mathrm{g} / \mathrm{ml})$ in the presence or absence of three different concentrations of $C$. fragile $(30,50$, and $100 \mu \mathrm{g} / \mathrm{ml})$ or ASA $(100 \mu \mathrm{M})$ under stirring conditions $(1,000 \mathrm{rpm})$ in an aggregometer. To measure kinase phosphorylation, platelets $\left(6 \times 10^{8} / \mathrm{ml}\right)$ were lysed in an equal volume of $2 \mathrm{x}$ ice-cold lysis buffer (TBS, pH 7.4, containing $2 \%$ Triton X-100, $0.1 \%$ SDS, $2 \mathrm{mM}$ EDTA, $2 \mathrm{mM} \quad \mathrm{Na}_{3} \mathrm{VO}_{4}$, phosphatase inhibitor cocktail, protease inhibitor cocktail, and $2 \mathrm{mM}$ phenylmethylsulfonyl fluoride) and sonicated. An equal amount of protein $(30 \mu \mathrm{g})$ was electrophoresed under reduced conditions and immunoblotted, followed by re-probing with different antibodies. In some experiment, spreading platelets were lysed in an equal volume of $2 \mathrm{x}$ ice-cold lysis buffer (TBS, $\mathrm{pH} 7.4$, containing 2\% Triton $\mathrm{X}-100,0.1 \%$ SDS, $2 \mathrm{mM}$ EDTA, $2 \mathrm{mM} \mathrm{Na}_{3} \mathrm{VO}_{4}$, phosphatase inhibitor cocktail, protease inhibitor cocktail, and $2 \mathrm{mM}$ phenylmethylsulfonyl fluoride) into reactions. The band density was measured by densitometry using ImageJ (v1.52a). The level of phosphorylation of each kinase was calculated via normalization of the density of antibodies against the phosphorylated kinases to that of the antibodies against total kinases.

$\mathrm{FeCl}_{3}$-induced in vivo thrombosis. Mice $(10$ mice of each group) were orally administered $0.5 \%$ low-viscosity CMC and/ or C. fragile (50 or $100 \mathrm{mg} / \mathrm{kg}, \mathrm{BW}$ ) or ASA (100 mg/kg, BW) twice a day for 3 days, with the administration occurring $30 \mathrm{~min}$ before the experiments on the third day. The left carotid artery was isolated, and then filter paper ( $2 \mathrm{~mm}$ diameter) soaked with $10 \%(460 \mathrm{mM}) \mathrm{FeCl}_{3}$ was placed on top of the artery for $2 \mathrm{~min}$. Blood flow was then monitored until 10 min after blood occlusion using a blood flowmeter ( $\mathrm{AD}$ instruments, Blood flowmeter).

Tail bleeding time. Mice (10 mice of each group) were orally administered $0.5 \%$ low-viscosity $\mathrm{CMC}$ and/or C. fragile (50 or $100 \mathrm{mg} / \mathrm{kg}, \mathrm{BW})$ or ASA (100 mg/kg, BW) twice a day for 3 days, with the administration occurring $30 \mathrm{~min}$ before the experiments on the third day. Body temperature was maintained at $37^{\circ} \mathrm{C}$ using a heating pad. Using a sharp razor blade, $5 \mathrm{~mm}$ of the tail was removed and held in a $15 \mathrm{ml}$ tube containing $13 \mathrm{ml}$ of PBS prewarmed to $37^{\circ} \mathrm{C}$. Tail bleeding was monitored and the time to cessation of blood flow was measured, and after $10 \mathrm{~min}$ the bleeding was stopped by cauterization. Blood loss was quantified by measuring the hemoglobin content of blood collected into $13 \mathrm{ml}$ of PBS. After centrifugation, the pellet of red blood cells was lysed with $5 \mathrm{ml}$ lysis buffer $\left(8.3 \mathrm{~g} / \mathrm{L} \mathrm{NH}_{4} \mathrm{Cl}, 1.0 \mathrm{~g} / \mathrm{L} \mathrm{KHCO}_{3}\right.$, and $0.037 \mathrm{~g} / \mathrm{L}$ EDTA), and the absorbance of the sample was measured at $575 \mathrm{~nm}$.

Statistical analysis. Data analysis was performed using GraphPad Prism 5. Statistical significance was assessed by ANOVA and Dunnett's test or Tukey's test for comparisons of multiple groups or Student's $t$-test for comparisons of two groups. A $p$ value of less than 0.05 was considered significant.

\section{RESULTS}

\section{Extract of $C$. fragile Inhibits Agonist-Induced Platelet Aggregation, ATP Secretion, and $\mathrm{TxB}_{2}$ Generation}

To investigate the effect of $C$. fragile on platelet function, we first examined platelet aggregation induced by various agonists, including thrombin, CRP, collagen, and ADP. We found that, compared to the vehicle control, platelets treated with $C$. fragile 
A

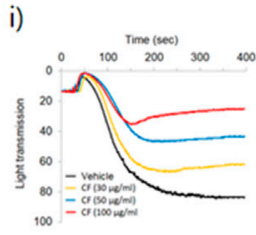

C

i)

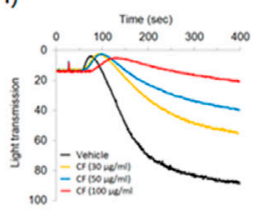

Thrombin $0.025 \mathrm{U} / \mathrm{ml}$

ii)

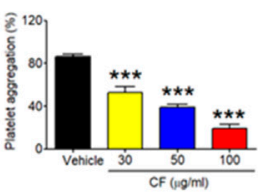

Collagen $2 \mu \mathrm{g} / \mathrm{ml}$

ii)

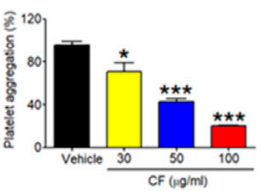

B

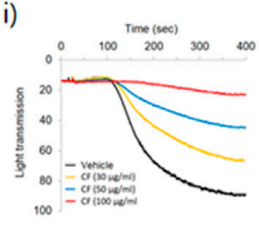

D

i)
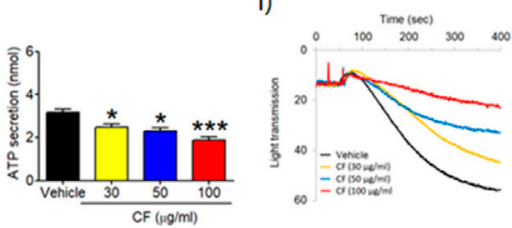

CRP $0.2 \mu \mathrm{g} / \mathrm{ml}$

ii)
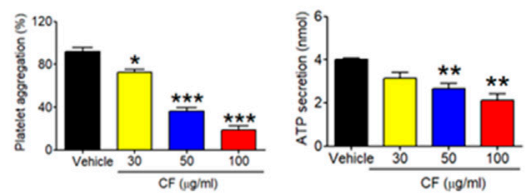

ADP $10 \mu \mathrm{M}$

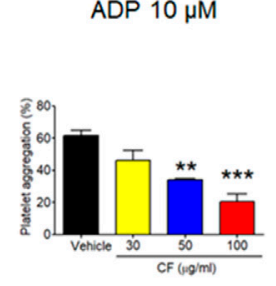

E

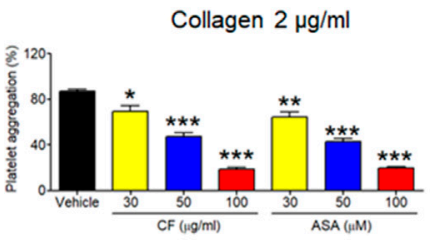

F

CRP $0.2 \mu \mathrm{g} / \mathrm{ml}$
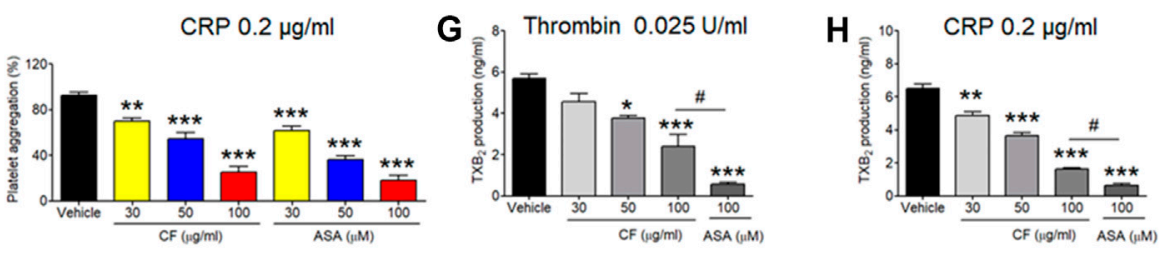

I
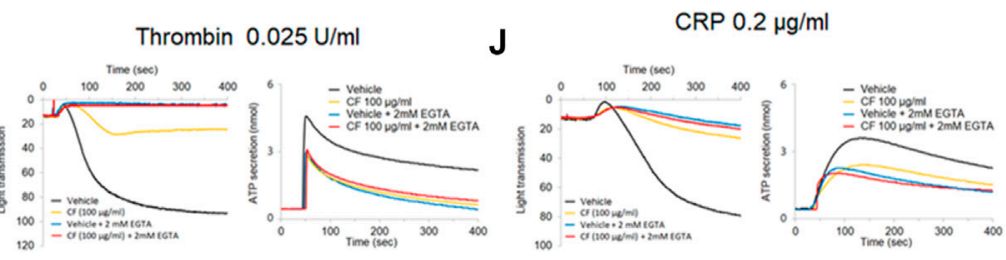

FIGURE 1 | Inhibitory effect of $C$. fragile on platelet aggregation, ATP secretion, and TxB2 production following stimulation with various agonists. Washed mouse platelets were preincubated with various concentrations of $C$. fragile $(30,50$, and $100 \mu \mathrm{g} / \mathrm{ml})$ for 10 min at $37^{\circ} \mathrm{C}$ and then stimulated with $0.025 \mathrm{U} / \mathrm{ml}$ Thrombin $(\mathbf{A})$, $0.2 \mu \mathrm{g} / \mathrm{ml} \mathrm{CRP}$ (B), $2 \mu \mathrm{g} / \mathrm{ml}$ Collagen (C), and $10 \mu \mathrm{M}$ ADP (D). In the ADP-induced aggregation assay, $30 \mu \mathrm{g} / \mathrm{ml}$ of human FG was added to the platelet suspension before ADP stimulation. In some experiments, washed platelets were pretreated with C. fragile (30, 50, and 100 $\mu \mathrm{g} / \mathrm{ml})$ or ASA ( 30,50 , and $100 \mu \mathrm{M})$ and then stimulated with $2 \mu \mathrm{g} / \mathrm{ml}$ Collagen (E) and $0.2 \mu \mathrm{g} / \mathrm{ml}$ CRP (F). Aggregation was measured for 5 min at $37^{\circ} \mathrm{C}$ under constant stirring $(1,000 \mathrm{rpm}) \mathrm{Conditions} \mathrm{in} \mathrm{a} \mathrm{platelet}$ aggregometer (Chrono-Log). (i) Platelet aggregation and quantitative graphs. The effect of $C$. Fragile on $T_{X} B 2$ generation was measured using a TXB2 ELISA assay kit $(\mathbf{G}, \mathbf{H})$. In the ADP secretion, washed platelets were preincubated with various concentrations of $\mathrm{C}$. fragile $(30,50$, and $100 \mu \mathrm{g} / \mathrm{ml})$ for $10 \mathrm{~min}$ at $37^{\circ} \mathrm{C}$ before adding a luciferin/luciferase reagent. After the luciferin/luciferase reagent added, platelets were stimulated with $0.025 \mathrm{U} / \mathrm{ml} \mathrm{Thrombin}(\mathbf{A}), 0.2 \mu \mathrm{g} / \mathrm{ml} \mathrm{CRP}$ (B), and $2 \mu \mathrm{g} / \mathrm{ml}$ Collagen (C). (ii) ATP secretion was measured using a luminometer. In other experiments, mouse platelets were preincubated with a high concentration of $C$. fragile $(100 \mu \mathrm{g} / \mathrm{ml})$ and activated with $0.025 \mathrm{U} / \mathrm{ml}$ Thrombin $\mathbf{( I )}$ and $0.2 \mu \mathrm{g} / \mathrm{ml} \mathrm{CRP}(\mathbf{J})$ in the presence of $20 \mathrm{mM}$ EGTA. Aggregation and ATP secretion were monitored with a platelet aggregometer. All data represent the mean \pm SD $(n=5) .{ }^{*}: p<0.05,{ }^{* *}: p<0.01$, and ${ }^{* \star *}: p<0.001$ vs. vehicle control after ANOVA and Dunnett's test.

had significantly decreased platelet aggregation induced by the intermediated concentration of thrombin $(\leq 0.025 \mathrm{U} / \mathrm{ml})$, CRP $(\leq 0.2 \mu \mathrm{g} / \mathrm{ml})$, collagen $(\leq 2 \mu \mathrm{g} / \mathrm{ml})$, and $\operatorname{ADP}(\leq 10 \mu \mathrm{M})$, in a concentration-dependent manner $(30,50$, and $100 \mu \mathrm{g} / \mathrm{ml})$ (Figures 1A-D, i). The reduced aggregation of $C$. fragiletreated platelets was similar to the inhibition of platelet aggregation by acetylsalicylic acid (ASA; 30, 50, and $100 \mu \mathrm{M}$ ) in response to collagen (Figure 1E) and CRP (Figure 1F) stimulation. Further, aqueous extraction of C. fragile was also investigated to elucidate the inhibitory effect on platelet aggregation. We found that $C$. fragile aqueous extract did not show an inhibitory effect on platelet aggregation (Supplementary Figure S1B). To further confirm the effect of $C$. fragile on platelet function, we examined adenosine triphosphate (ATP) secretion. We observed that compared to the vehicle control, C. fragile treatment dose-dependently $(30,50, \quad$ and $100 \mu \mathrm{g} / \mathrm{ml})$ inhibited ATP secretion induced by thrombin $(0.025 \mathrm{U} / \mathrm{ml})$, CRP $(0.2 \mu \mathrm{g} / \mathrm{ml})$, and collagen $(2 \mu \mathrm{g} / \mathrm{ml})$ (Figures 1A-C, ii). We assessed $\mathrm{TxB}_{2}$ generation after stimulation by thrombin $(0.025 \mathrm{U} / \mathrm{ml})$ and CRP $(0.2 \mu \mathrm{g} / \mathrm{ml})$. The levels of $\mathrm{TxB}_{2}$ were dramatically elevated by both agonists, but treatment with $C$. fragile showed potent inhibition of agonist-induced $\mathrm{TxB}_{2}$ generation (Figures 1G,H). These results suggest that $C$. fragile plays a crucial role in stimulating platelet aggregation, ATP secretion, and $\mathrm{TxB}_{2}$ generation.

To further examine the way in which $C$. fragile regulates ATP secretion, $C$. fragile-pretreated mouse platelets were incubated with $2 \mathrm{mM}$ ethylene glycol-bis( $\beta$-aminoethyl ether)- $N, N, N^{\prime}, N^{\prime}$ tetraacetic acid (EGTA) to prevent the interaction of FG with activated $\alpha \operatorname{IIb} \beta 3$ integrin and then stimulated with thrombin 

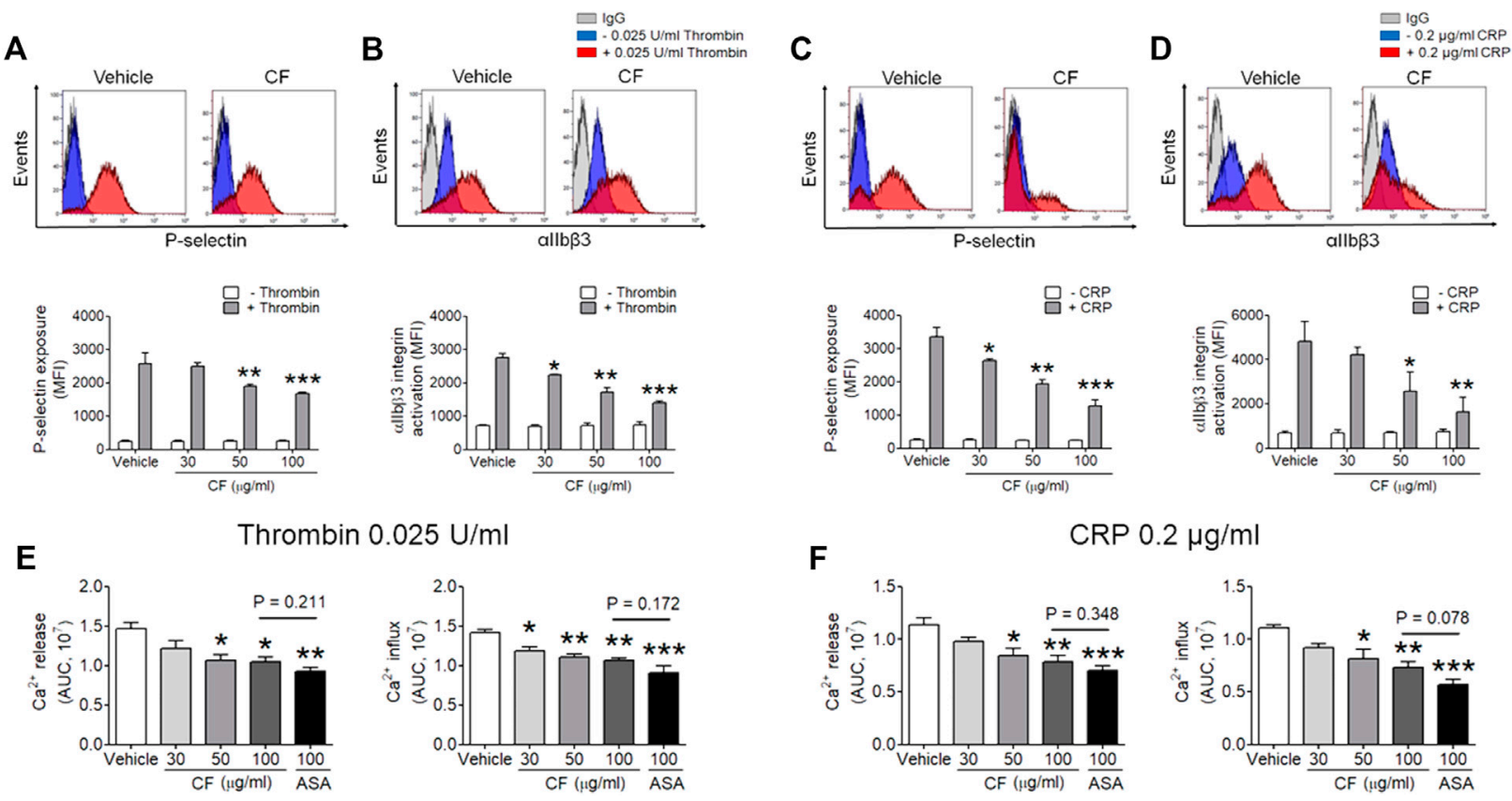

FIGURE 2 | Inhibitory effect of $C$. fragile on P-selectin exposure, allb $\beta 3$ integrin activation, and $\mathrm{Ca}^{2+}$ mobilization during platelet activation. Mouse platelets were pre-treated with the concentration of $C$. fragile $(30,50$, and $100 \mu \mathrm{g} / \mathrm{ml})$, and stimulated with $0.025 \mathrm{U} / \mathrm{ml}$ thrombin (A,B) or $0.2 \mu \mathrm{g} / \mathrm{ml}$ CRP (C,D). P-selectin exposure and

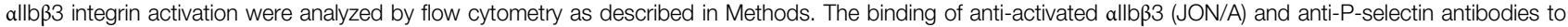
platelets was calculated by the ratio of the geometric mean fluorescence intensity (MFI) value of antibodies to that of control lgG. Data represent mean \pm SD $(n=5)$. ${ }^{*}: p<0.05,{ }^{* *}: p<0.01$, and ${ }^{* * *}: p<0.001$ vs vehicle control after ANOVA and Dunnett's test. In $\mathrm{Ca}^{2+}$ mobilization assay, mouse platelets were resuspended in HEPESTyrode buffer without $1 \mathrm{mM} \mathrm{CaCl}_{2}$ and preincubated with various concentration of $C$. fragile $(30,50$, and $100 \mu \mathrm{g} / \mathrm{ml})$ or ASA (100 $\left.\mu \mathrm{M}\right)$ for $10 \mathrm{~min}$ at $37^{\circ} \mathrm{C}$, and then incubated with a calcium-sensitive dye for $30 \mathrm{~min}$ at $37^{\circ} \mathrm{C}$ in the dark. After treatment with a $\mathrm{Ca}^{2+}$ dye, platelets were stimulated with platelets were stimulated with $0.025 \mathrm{U} / \mathrm{ml}$ Thrombin (E) and $0.2 \mathrm{\mu g} / \mathrm{ml}$ CRP (F) for 20 min and $2 \mathrm{mM} \mathrm{CaCl}_{2}$ was then added for $20 \mathrm{~min}$ and $2 \mathrm{mM} \mathrm{CaCl}_{2}$ was then added. Intracellular Ca ${ }^{2+}$ release and influx were measured and quantified by the AUC (arbitrary units). Data represent the mean $\pm \mathrm{SD}(n=5){ }^{*}: p<0.05,{ }^{* \star}: p<0.01$, and ${ }^{\star \star *}: p<0.001 \mathrm{vs}$. vehicle control and a $p$ value between two groups after ANOVA and Turkey's test.

$(0.025 \mathrm{U} / \mathrm{ml})$ and CRP $(0.2 \mu \mathrm{g} / \mathrm{ml})$. Neither the vehicle nor the $C$. fragile-treated platelets aggregated but released an equal amount of ATP (Figures 1I,J). Since ATP secretion is only derived from agonist-induced platelet activation in the presence of EGTA (Kim et al., 2013), these results suggest that $C$. fragile reduces the interaction of FG with activated $\alpha \mathrm{IIb} \beta 3$ integrin.

\section{C. fragile Inhibits P-Selectin Exposure, allbß3 Integrin Activation, and $\mathrm{Ca}^{2+}$ Mobilization During Cell Activation}

Next, we sought to investigate whether $C$. fragile plays an important role in platelet activation. We assessed the contribution of $C$. fragile to P-selectin exposure, $\alpha \mathrm{IIb} \beta 3$ integrin activation, and $\mathrm{Ca}^{2+}$ mobilization during cell activation. Treatment with C. fragile $(30,50$, and $100 \mu \mathrm{g} / \mathrm{ml})$ significantly inhibited P-selectin exposure (Figures 2A,C), aIIb $\beta 3$ integrin activation (Figures 2B,D), and $\mathrm{Ca}^{2+}$ mobilization (Figures 2E,F) in response to thrombin $(0.025 \mathrm{U} / \mathrm{ml})$ and CRP $(0.2 \mu \mathrm{g} / \mathrm{ml})$ stimulation, in a dosedependent manner. These results suggest that $C$. fragile plays an important role in regulating platelet activation through its effects on granule secretion, $\mathrm{Ca}^{2+}$ mobilization, and $\alpha \mathrm{IIb} \beta 3$ integrin activation.

\section{Effects of C. fragile on Platelet Spreading and Clot Retraction Assay}

Since C. fragile treatment regulated platelet aggregation and ATP secretion through the regulation of the activation of $\alpha \operatorname{IIb} \beta 3$ integrin, we further examined whether outside-in signaling events were affected by the treatment of $C$. fragile using platelet spreading assays. We found that compared to the vehicle control, C. fragile treatment dose-dependently (30, 50, and $100 \mu \mathrm{g} / \mathrm{ml}$ ) prevented platelet spreading on immobilized FG (Figure 3A). Although the number of adherent platelets showed a moderate reduction following treatment with a low dose of $C$. fragile, it showed a significant reduction in high-dose $C$. fragile treatment (Figures 3A-D). The lamellipodial actin assembly and surface coverage were markedly reduced by $C$. fragile treatment in a concentration-dependent manner (Figures 3B-D). Platelet spreading and clot retraction assays reflect the processing of early and late- $\alpha \mathrm{IIb} \beta 3$ integrin outside-in signaling, respectively (Flevaris et al., 2007). The assessment derived from the earliest event of integrin $\alpha \mathrm{IIb} \beta 3$ mediated outside-in signaling displayed that the activated integrin such as integrin $\beta 3$ phosphorylation was significantly suppressed by $C$. fragile treatment. Besides the inhibitory effect on FAK phosphorylation, C. fragile treatment also inhibited the outside-in signaling by negatively regulating the Src-AKT signaling pathways (Figures 3G,H). Further, we 
A

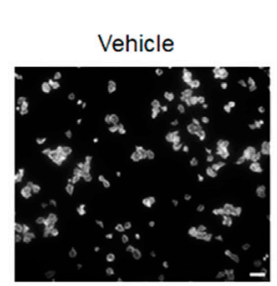

$\mathrm{CF}(\mu \mathrm{g} / \mathrm{ml})$

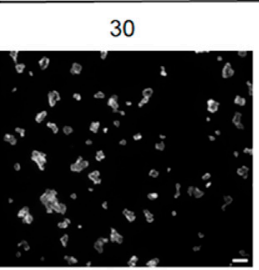

50

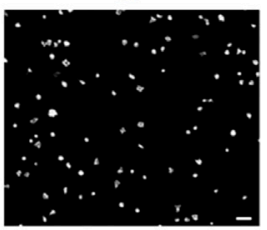

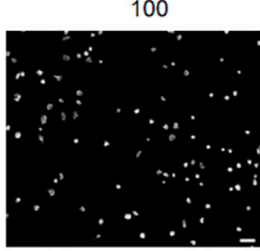

C
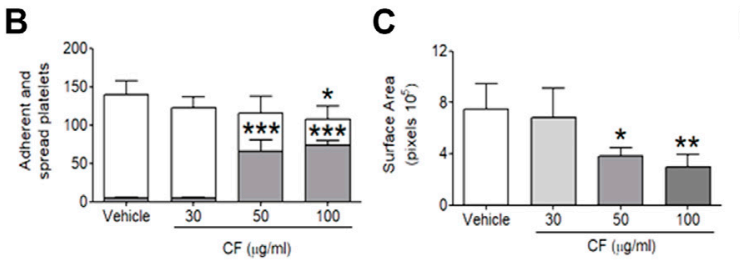

D
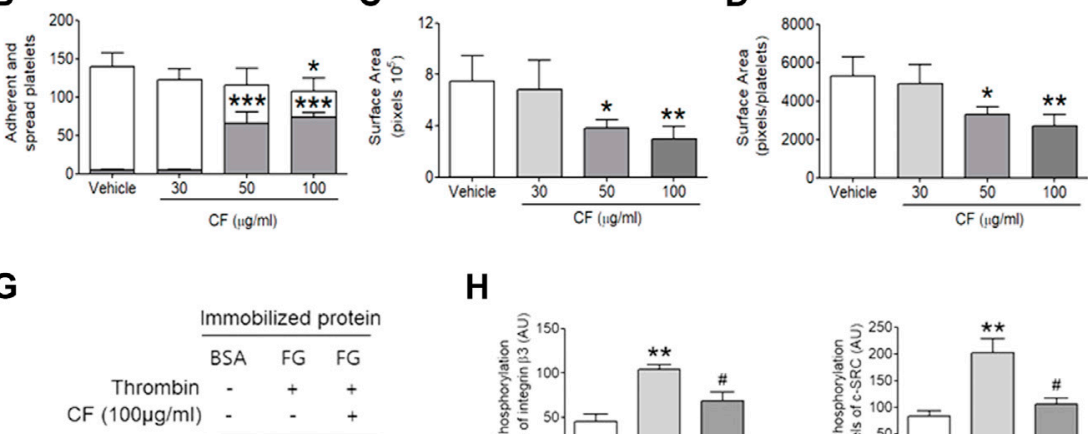

Phospho-integrin $\beta 3=$

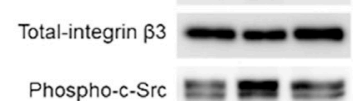

Phospho-c-Src $\mathrm{Ez}=$

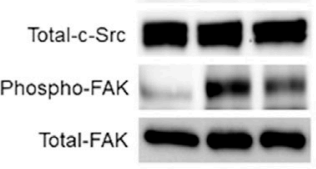

Phospho-AKT

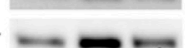

H
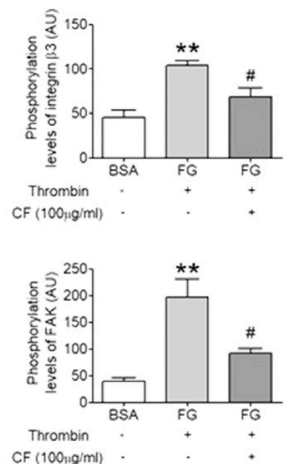
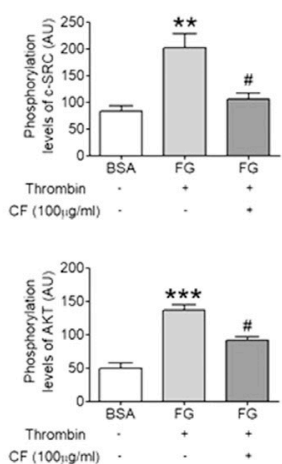

E

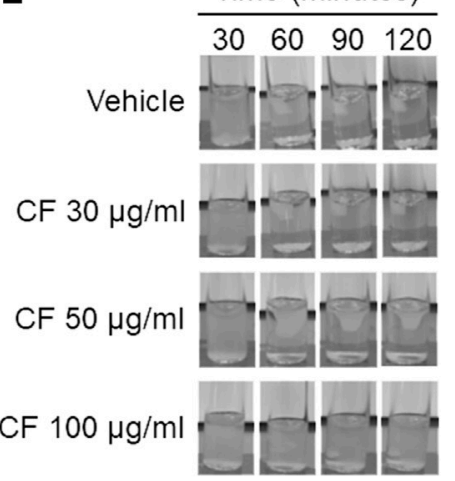

$\mathbf{F}$

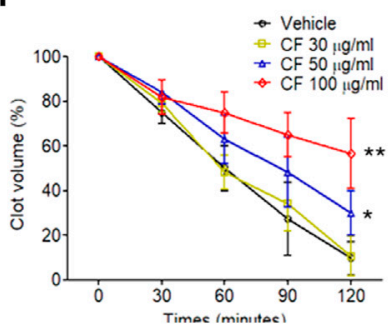

Total-AKT

FIGURE 3 | C. fragile shows a defective allb $\beta 3$ integrin-dependent spreading on fibrinogen and fibrin clot retraction. Washed platelets pre-treated with various concentrations of $\mathrm{C}$. fragile $(30,50$, and $100 \mu \mathrm{g} / \mathrm{ml})$ or vehicle control $\left(0.01 \%\right.$ DMSO) and incubated on FG-coated surfaces for $2 \mathrm{~h}$ at $37^{\circ} \mathrm{C}$. Adherent and spread platelets were stained with rhodamine-conjugated phalloidin. (A) Representative images. Scale bars: $10 \mu m$ (white). (B) Number of adherents (but not spread, gray bars) and fully spread (white bars). Platelet spreading was analyzed by the surface area (C) which was measured by the number of pixels divided by the number of platelets (D) in the field. (E,F) Mouse platelets were incubated with various concentrations of C. fragile (30,50, and 100 $\mu \mathrm{g} / \mathrm{ml})$ or vehicle control (0.01\% DMSO) and fibrin clot retraction was assessed up to $2 \mathrm{~h}$ after addition of thrombin, fibrinogen, and $\mathrm{CaCl}_{2}$. (E) Representative photographs and (F) summary data were presented. (G,H) The phosphorylation levels of integrin $\beta 3, c-S r c, F A K$, and AKT in lysed spreading platelet. *: $p<0.05,{ }^{* *}: p<0.01$, and ${ }^{* \star *}: p<0.001$ vs. vehicle control and \#: $p<0.05$ after ANOVA and Dunnett's test. Data represent mean $\pm \operatorname{SD}(n=5)$.

investigated the effect of $C$. fragile on clot retraction. Consistent with the ablated platelet spreading, $C$. fragile showed a significant impairment of clot retraction compared to vehicle control (Figures 3E,F). These results suggest that the effects of $C$. fragile are likely limited to early and late- $\alpha \operatorname{IIb} \beta 3$ integrin outside-in signaling and that these effects may occur through the regulation of the ligand-binding activity of $\alpha \mathrm{IIb} \beta 3$ integrin.

\section{C. fragile Plays an Important Role in Regulating allb $\beta 3$ Integrin Outside-in Signaling}

The activation of $\alpha \operatorname{IIb} \beta 3$ integrin outside-in signaling leads to the phosphorylation of Src, Syk, and PLC $\gamma 2$ (Wonerow et al.,
2003; Suzuki-Inoue et al., 2007a; Battram et al., 2017). Therefore, we measured the phosphorylation status of these signaling intermediates. Consistent with the defective platelet spreading and clot retraction, $C$. fragile-treated platelets exhibited a significant reduction of Src, Syk, and PLC $\gamma 2$ phosphorylation following thrombin (Figures 4A,B) and CRP (Figures 4C,D) stimulation compared with that of vehicle control-treated platelets. These results demonstrated that $C$. fragile treatment has a specific role in the regulation of platelet functions involving the c-Src-Syk-PLC $\gamma 2$ signaling pathway.

Members of the PI3K-AKT-mitogen-activated protein kinases (MAPK) family, p38, and extracellular signal-regulated kinase (ERK) have been reported to play a pivotal role in the integrin 
A

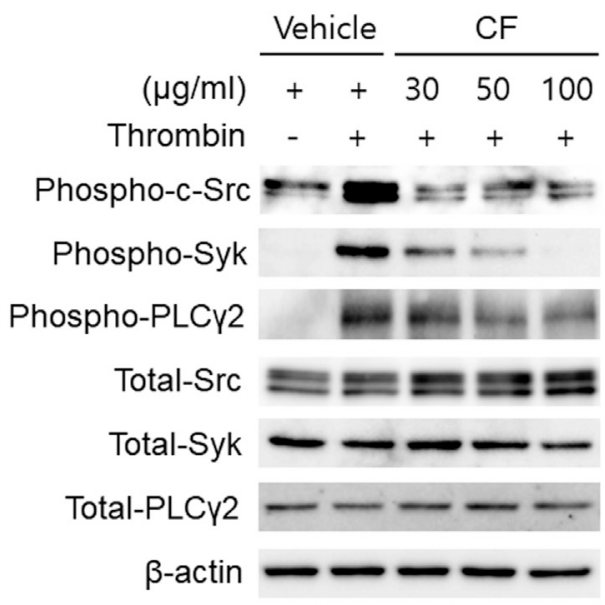

C

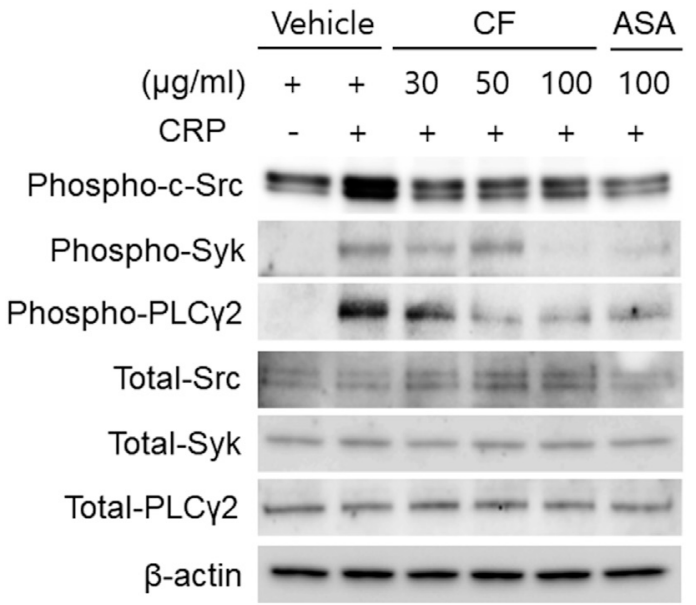

B
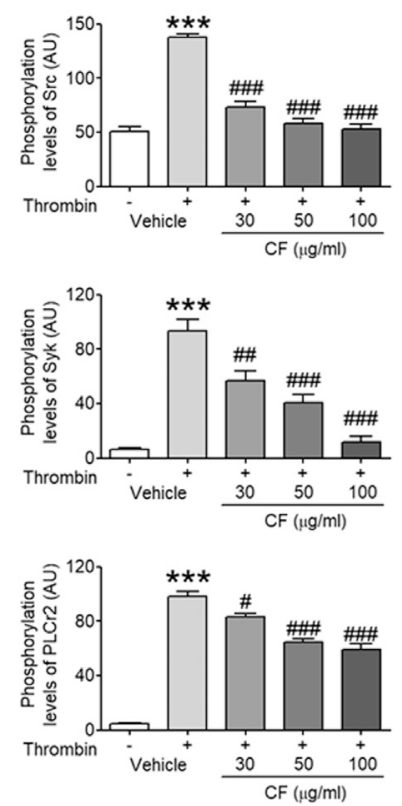

D
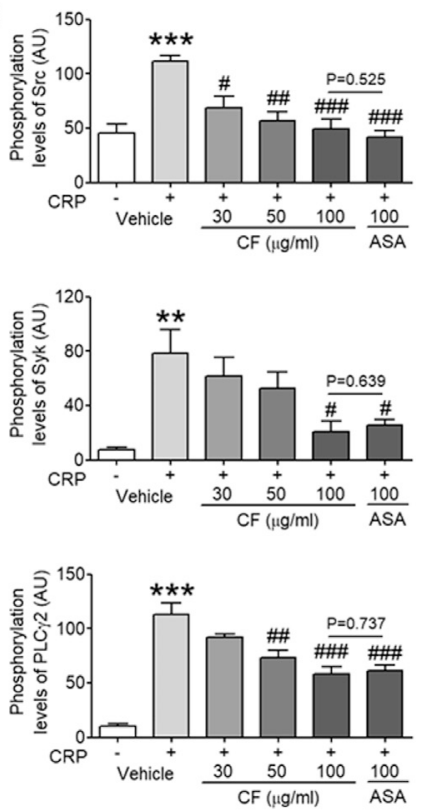

FIGURE 4 | C. fragile attenuated phosphorylation of c-Src, Syk, PLC 2 2, PI3K, AKT, p38, and ERK after thrombin and CRP stimulation. Mouse platelets were pre-treated with various concentrations of $C$. fragile (30,50, and $100 \mu \mathrm{g} / \mathrm{ml})$, and stimulated with $0.025 \mathrm{U} / \mathrm{ml}$ Thrombin (A,B). In some experiments, washed platelets were pretreated with C. fragile (30, 50 , and $100 \mu \mathrm{g} / \mathrm{ml})$ or ASA $(100 \mu \mathrm{M}$ ) and then stimulated with $0.2 \mu \mathrm{g} / \mathrm{ml}$ CRP (C-F). Equal amounts (30 $\mu \mathrm{g})$ of cell lysate protein were immunoblotted to determine specific inhibition of c-Src, Syk, PLCr2, PI3K, AKT, p38, and ERK phosphorylation. Representative blots (A,C,E). Quantitative graphs (B,D,F). Data represent the mean \pm SD $(n=5)$. **:p<0.01 and **: $p<0.001$ vs. vehicle control (unstimulated) after Student's t-test, and. \#:p < 0.05, \#\#:p<0.01, and \#\#\#:p<0.001 vs. vehicle control (stimulated) after ANOVA and Turkey's test.

outside-in signaling pathway (Watanabe et al., 2003; Flevaris et al., 2009). We, therefore, investigated the underlying molecular mechanism of the inhibitory effect of $C$. fragile on platelet activation. Biochemical analysis using platelet lysates indicated that compared with vehicle control, pretreatment of platelets with C. fragile significantly reduced the phosphorylation of PI3K,
AKT, p38, and ERK following CRP stimulation (Figures $4 \mathrm{E}, \mathrm{F})$. These results suggested that $C$. fragile might function as a negative regulator of PI3K-AKT-MAPK signaling, to inhibit agonist-induced platelet activation. These findings support the hypothesis that $C$. fragile has a pivotal role in the regulation of platelet integrin $\alpha \operatorname{IIb} \beta 3$ outside-in signaling. 


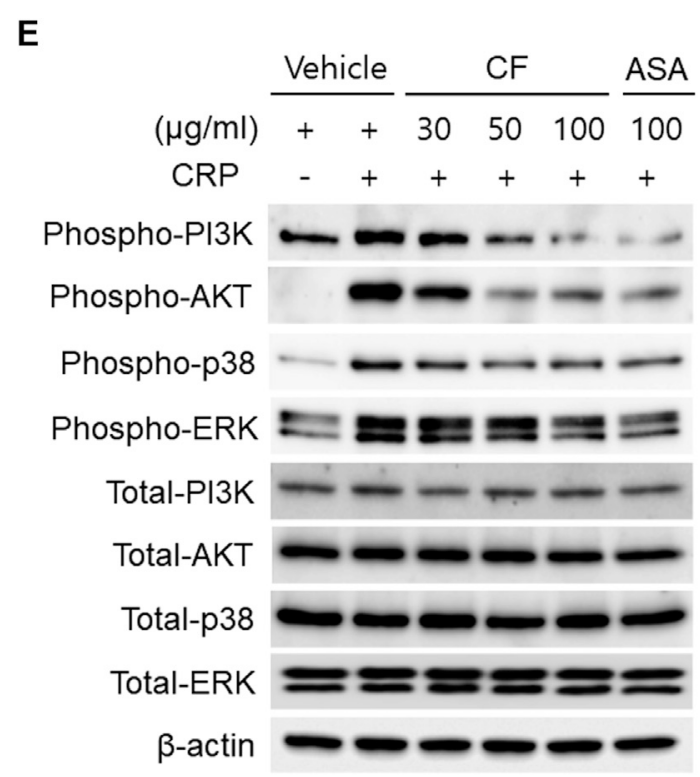

$\mathbf{F}$
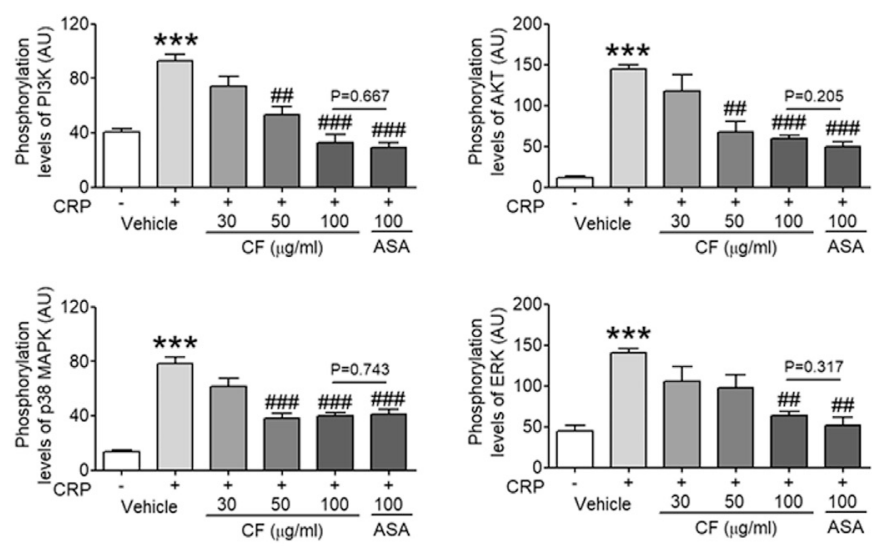

FIGURE 4 | Continued.

\section{C. fragile Inhibits in vivo $\mathrm{FeCl}_{3}$-Induced Thrombus Formation, but Not Hemostasis}

The $\mathrm{FeCl}_{3}$-induced vascular injury model has been widely used to study thrombogenesis (Eckly et al., 2011). We investigated whether treatment with $C$. fragile had an inhibitory effect on $\mathrm{FeCl}_{3}$-induced thrombus formation. Thrombus formation was evaluated using $10 \%(460 \mathrm{mM})$ $\mathrm{FeCl}_{3}$. The carotid artery occlusion time in the oral administration of C. fragile $(50$ and $100 \mathrm{mg} / \mathrm{kg}$, body weight (BW)) was significantly prolonged compared to control (Figure 5A). The oral administration of $C$. fragile $(100 \mathrm{mg} / \mathrm{kg}, \quad B W)$ showed a blood flow prolongation close to that induced by the positive control (ASA, $100 \mathrm{mg} / \mathrm{kg}, \mathrm{BW}$ ). We investigated whether the oral administration of C. fragile (50 and $100 \mathrm{mg} / \mathrm{kg}, \mathrm{BW})$ influenced hemostatic function. We observed that tail bleeding times were similar between the $C$. fragile- and control-treated groups (Figure 5B). Blood collected from the site of amputation and quantified by hemoglobin content revealed no difference in blood loss between the C. fragileand control-treated groups (Figure 5B). However, the oral administration of $100 \mathrm{mg} / \mathrm{kg}$ ASA led to a much longer bleeding time and increased hemoglobin content than that exhibited in the $C$. fragile-treated mice and the vehicle controls (Figure 5B). These results suggest that $C$. fragile inhibits $\mathrm{FeCl}_{3}$-induced arterial thrombosis but not hemostasis in vivo.

\section{Content Analysis of Phytol in C. fragile Ethanol Extract}

The component of the phytol that contributed to the antiplatelet effect in C. fragile ethanol extract was determined using GC-MS analysis. Phytol- 1 and phytol-2 were successively detected under the GC-MS conditions we described at 15.769 and $16.124 \mathrm{~min}$, respectively, and were found in $C$. fragile ethanol extract at the same retention times, 15.777 and $16.128 \mathrm{~min}$. However, it is not yet clear which peak was trans-phytol and which was cis-phytol (Figures 6A,C). The calibration curve was $y=10.52101 x-1,093.766$, with a coefficient of determination of 0.9993 at injected concentrations of $100-5,000 \mu \mathrm{g} / \mathrm{kg}$ (Figure 6B). The total phytol isomer content was $160.8 \mathrm{mg} / \mathrm{kg}$; it was one of the most abundant compounds in $C$. fragile ethanol extract.

\section{DISCUSSION}

Platelet-derived thrombus formation during vascular damage is the main cause of cardiovascular diseases such as myocardial infarction and ischemic stroke. Although antiplatelet drugs have been widely used in the treatment of thrombotic disorders, these have limited efficacy and concerns have been expressed about their safety (McFadyen et al., 2018). Hence, the development of new antiplatelet drugs is required for the improved treatment of thrombotic disorders. Marine algae could be good therapeutic agents because they are a source of natural derivatives and edible nutrients and a potential source of bioactive compounds, so the risk of adverse effects is reduced. However, few studies have reported on some marine algae and their probable antithrombotic effects (Trento et al., 2001). In the present study, therefore, we evaluated the antithrombotic properties of Codium fragile (Suringar) Hariot, which has been used as a therapeutic agent for its anti-inflammatory and antioxidant effects in traditional medicine (Lee et al., 2013; Dilshara et al., 2016). We demonstrated that treatment with $C$. fragile inhibits thrombus formation in vivo and in vitro. Platelet activation 
A
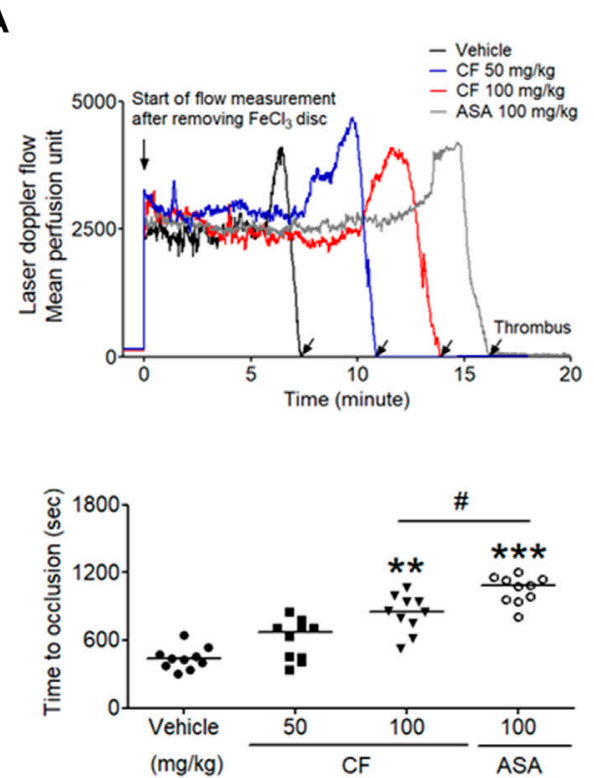

B
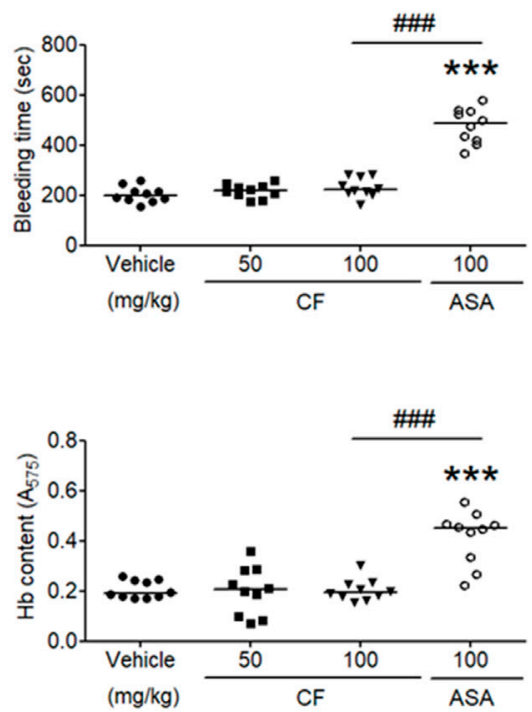

FIGURE 5 | C. fragile delayed $\mathrm{FeCl}_{3}{ }^{-}$induced arterial thrombus formation but not hemostasis. FeCl 3 -induced arterial thrombus formation was performed as described in Methods. After oral administration of 0.5\% low-viscosity CMC and/or C. fragile (50 or 100 mg/kg, BW) or ASA (100 mg/kg, BW) twice a day for 3 days (A), the mouse carotid artery was treated with $10 \% \mathrm{FeCl}_{3}$ for $2 \mathrm{~min}$, and blood flow traces were monitored until stable occlusion took place. Horizontal bars represent the median occlusion time $(n=10)$. In the bleeding time assay, tails of the vehicle (circle), a low dose of $C$. fragile (50 mg/kg, square), a high dose of $C$. fragile (100 mg/kg, reverse triangle), and ASA (open circle) treated mice were amputated (B), and the bleeding time and $\mathrm{Hb}$ content were monitored as described in Methods. Horizontal bars represent the median of occlusion and bleeding times for each group of animals $(n=10)$. ${ }^{* *}: p<0.01$ and ${ }^{* \star *}: p<0.001$ vs. vehicle control and \#: $p<0.05$ and \#\#\#: $<0.001$ between two groups after ANOVA and Turkey's test.

and aggregation following stimulation with various agonists have been markedly reduced by treatment with $C$. fragile, in a dose-dependent manner. Thus, this study indicated an important role for $C$. fragile in platelet activation and aggregation.

Integrins are heterodimeric transmembrane proteins expressed on the cell surface. They act as adhesion receptors that trigger intracellular signaling pathways by binding extracellular ligands (Hynes, 2002). On the surface of platelets, integrin $\alpha \mathrm{IIb} \beta 3$ acts as a bidirectional receptor for inside-out and outside-in signaling and plays a pivotal role in initiating downstream signaling that triggers intracellular processes such as platelet spreading, adhesion, clot retraction, and aggregation, which leads to platelet thrombus formation and stabilization (Hynes, 2002; Huang et al., 2019). There is increasing evidence of the importance of $\alpha \mathrm{IIb} \beta 3$ integrin-mediated outside-in signaling in thrombotic disorders. The current understanding of thrombogenesis suggested that the inhibition of outside-in
A<smiles>CC(=CCO)CCC[C@@H](C)CCC[C@@H](C)CCCC(C)C</smiles><smiles>CC(C)=CCC[C@H](C)CCC[C@@H](C)CCCC(C)C</smiles>

B

\begin{tabular}{|c|c|c|c|c|c|}
\hline Compound & Range(ug/kg, ppb) & Regression equation & $\begin{array}{l}\text { Coefficient of } \\
\text { determination }\end{array}$ & $\operatorname{LOD}(\mathrm{mg} / \mathrm{kg})$ & LOQ(mg/kg) \\
\hline Phytol-1 & \multirow{2}{*}{$100.0 \sim 5000.0$} & \multirow{2}{*}{$10.5210 \times-1093.766$} & \multirow{2}{*}{0.9993} & 0.031 & 0.093 \\
\hline Phytol-2 & & & & 0.027 & 0.081 \\
\hline
\end{tabular}

C
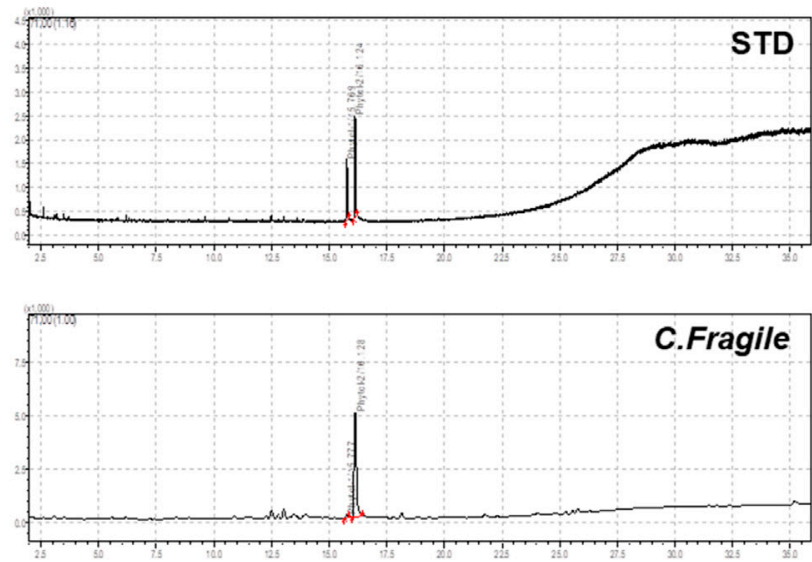

FIGURE 6 | Analysis of C. fragile ethanol extract by using GC-MS (A) Structure of trans-phytol and cis-phytol. (B) Regression equations, LODs, and LOQs of phytol-1 and phytol-2. (C) GC-MS chromatogram of a mixture of phytol isomers standard and C. fragile ethanol extract. 
signaling could be a valuable approach to the development of therapeutics with antiplatelet activities, without causing excessive hemorrhage (Shen et al., 2013; Estevez et al., 2015). Our study demonstrated that treatment with $C$. fragile downregulated integrin $\alpha \operatorname{IIb} \beta 3$ outside-in signaling, thus diminishing platelet spreading on immobilized FG and clot retraction, which may contribute to the effective inhibition of the development of thrombogenesis.

Due to the wide range of biological activities, natural products have long been used as one of the most important strategies for treating and preventing cardiovascular disease (Al Disi et al., 2015; Shaito et al., 2020). However, it is currently difficult to determine to what extent the in vitro effects produced can be extrapolated to the in vivo situation (Maaliki et al., 2019). In order to investigate, therefore, the effect of oral administration of $C$. fragile on thrombus formation, we used a mouse model of $\mathrm{FeCl}_{3}$ induced arterial thrombosis, which has been widely used as an experimental arterial thrombosis model. C. fragile prevented thrombotic occlusion due to $\mathrm{FeCl}_{3}$-induced artery injury. The tail bleeding time was not significantly higher in mice treated with C. fragile than in control mice. These results indicate that $C$. fragile can exert antiplatelet and antithrombotic effects without affecting hemostasis.

Although it is unclear how C. fragile regulates platelet responses to all agonists, this regulation is probably due to the different key components of $C$. fragile. In this study, we confirmed the content of the major compound in the extract using GC-MS analysis. Phytol was the major component in $C$. fragile extract, with content of $160.8 \mathrm{mg} / \mathrm{kg}$. Phytol is one of the acyclic diterpene alcohols and is a precursor of a synthetic form of vitamin E. Vitamin E is a fat-soluble vitamin and has shown antiplatelet activity when used in conjunction with aspirin (Celestini et al., 2002). Therefore, we suggest that the antiplatelet activity of $C$. fragile ethanol extract was contributed by the high content of phytol in C. fragile. Extract of $C$. fragile has been shown to produce anticoagulant properties via the fibrinolytic activities of a biofunctional serine protease. Although it is not known which components of $C$. fragile are important for thrombolytic activity in vitro and in vivo, we speculate that most polyphenolic compounds might play important roles in platelet function. However, the synergy and additive effects of the individual components of $C$. fragile are still unclear. In order to study the pharmacological action of $C$. fragile and its interactions with different targets, a deeper understating of the pharmacokinetics and efficacy of the key components of C. fragile is necessary.

In conclusion, our study found that $C$. fragile effectively attenuated platelet activation and thrombus formation by downregulating $\alpha \operatorname{IIb} \beta 3$ signaling, without affecting hemostasis.

\section{REFERENCES}

Al Disi, S. S., Anwar, M. A., and Eid, A. H. (2015). Anti-hypertensive Herbs and Their Mechanisms of Action: Part I. Front. Pharmacol. 6, 323. doi:10.3389/ fphar.2015.00323
Therefore, it may have the potential to be an antithrombotic agent for the treatment of arterial thrombotic disorders and the prevention of thrombotic diseases.

\section{DATA AVAILABILITY STATEMENT}

The raw data supporting the conclusion of this article will be made available by the authors, without undue reservation.

\section{ETHICS STATEMENT}

The animal study was reviewed and approved by the study was conducted in strict accordance with the recommendations in the Guide for the Care and Use of Laboratory Animals from the National Animal Welfare Law of Korea. All animal operations in this study were approved by the Ethics Committee of the Korea Institute of Oriental Medicine. All animal operations in this study were conducted according to the guidelines of the Animal Management Committee of the Korea Institute of Oriental Medicine.

\section{AUTHOR CONTRIBUTIONS}

TK: designed and performed research, collected and analyzed data, and wrote the manuscript; YK: performed research, provided important data; KK: initiated and designed research, analyzed data, and wrote the manuscript; all authors reviewed the manuscript.

\section{FUNDING}

This work has been supported by Grant NRN2011120 awarded to Korea Institute of Marine Science and Technology Promotion from the Ministry of Oceans and Fisheries, Republic of Korea. This work has been supported by Grant 20200219 awarded to Korea Institute of Marine Science and Technology Promotion from the Ministry of Oceans and Fisheries, and Grant KSN2021230 awarded to Korea Institute of Oriental Medicine (KIOM) from Ministry of Science and ICT, Republic of Korea.

\section{SUPPLEMENTARY MATERIAL}

The Supplementary Material for this article can be found online at: https://www.frontiersin.org/articles/10.3389/fphar.2021.685948/ full\#supplementary-material

Alexander, K. P., and Peterson, E. D. (2010). Minimizing the Risks of Anticoagulants and Platelet Inhibitors. Circulation 121, 1960-1970. doi:10.1161/circulationaha.109.853135

Arias-Salgado, E. G., Lizano, S., Sarkar, S., Brugge, J. S., Ginsberg, M. H., and Shattil, S. J. (2003). Src Kinase Activation by Direct Interaction with the Integrin Cytoplasmic Domain. Proc. Natl. Acad. Sci. 100, 13298-13302. doi:10.1073/pnas.2336149100 
Battram, A. M., Durrant, T. N., Agbani, E. O., Heesom, K. J., Paul, D. S., Piatt, R., et al. (2017). The Phosphatidylinositol 3,4,5-trisphosphate (PI $(3,4,5) \mathrm{P} 3)$ Binder Rasa3 Regulates Phosphoinositide 3-kinase (PI3K)-dependent Integrin aIIb $\beta 3$ Outside-In Signaling. J. Biol. Chem. 292, 1691-1704. doi:10.1074/ jbc.m116.746867

Bennett, J. S. (2005). Structure and Function of the Platelet Integrin IIb 3. J. Clin. Invest. 115, 3363-3369. doi:10.1172/jci26989

Celestini, A., Pulcinelli, F. M., Pignatelli, P., Lenti, L., Frati, G., Gazzaniga, P. P., et al. (2002). Vitamin E Potentiates the Antiplatelet Activity of Aspirin in Collagen-Stimulated Platelets. Haematologica 87, 420-426.

Dilshara, M. G., Jayasooriya, R. G. P. T., Kang, C.-H., Choi, Y.-H., and Kim, G.-Y. (2016). Methanol Extract of Codium Fragile Inhibits Tumor Necrosis Factora-Induced Matrix Metalloproteinase-9 and Invasiveness of MDA-MB-231 Cells by Suppressing Nuclear Factor-Kb Activation. Asian Pac. J. Trop. Med. 9, 535-541. doi:10.1016/j.apjtm.2016.04.010

Durrant, T. N., Van Den Bosch, M. T., and Hers, I. (2017). Integrin aIIb $\beta 3$ OutsideIn Signaling. Blood 130, 1607-1619. doi:10.1182/blood-2017-03-773614

Eckly, A., Hechler, B., Freund, M., Zerr, M., Cazenave, J.-P., Lanza, F., et al. (2011). Mechanisms Underlying FeCl3-Induced Arterial Thrombosis. J. Thromb. Haemost. 9, 779-789. doi:10.1111/j.1538-7836.2011.04218.x

Estevez, B., Shen, B., and Du, X. (2015). Targeting Integrin and Integrin Signaling in Treating Thrombosis. Arterioscler Thromb. Vasc. Biol. 35, 24-29. doi:10.1161/atvbaha.114.303411

Falk, E. (2006). Pathogenesis of Atherosclerosis. J. Am. Coll. Cardiol. 47, C7-C12. doi:10.1016/j.jacc.2005.09.068

Flevaris, P., Li, Z., Zhang, G., Zheng, Y., Liu, J., and Du, X. (2009). Two Distinct Roles of Mitogen-Activated Protein Kinases in Platelets and a Novel RaclMAPK-dependent Integrin Outside-In Retractile Signaling Pathway. Blood 113, 893-901. doi:10.1182/blood-2008-05-155978

Flevaris, P., Stojanovic, A., Gong, H., Chishti, A., Welch, E., and Du, X. (2007). A Molecular Switch that Controls Cell Spreading and Retraction. J. Cel Biol 179, 553-565. doi:10.1083/jcb.200703185

Gong, H., Shen, B., Flevaris, P., Chow, C., Lam, S. C.-T., Voyno-Yasenetskaya, T. A., et al. (2010). G Protein Subunit G 13 Binds to Integrin IIb 3 and Mediates Integrin "Outside-In" Signaling. Science 327, 340-343. doi:10.1126/ science.1174779

Huang, J., Li, X., Shi, X., Zhu, M., Wang, J., Huang, S., et al. (2019). Platelet Integrin aIIb 33 : Signal Transduction, Regulation, and its Therapeutic Targeting. J. Hematol. Oncol. 12, 26. doi:10.1186/s13045-019-0709-6

Hynes, R. O. (2002). Integrins. Cell 110, 673-687. doi:10.1016/s0092-8674(02) 00971-6

Kang, C.-H., Choi, Y. H., Park, S.-Y., and Kim, G.-Y. (2012). Anti-inflammatory Effects of Methanol Extract of Codium Fragile in LipopolysaccharideStimulated RAW 264.7 Cells. J. Med. Food 15, 44-50. doi:10.1089/ jmf.2010.1540

Kim, K., Do, H. J., Oh, T. W., Kim, K. Y., Kim, T. H., Ma, J. Y., et al. (2018). Antiplatelet and Antithrombotic Activity of a Traditional Medicine, Hwangryunhaedok-Tang. Front. Pharmacol. 9, 1502. doi:10.3389/ fphar.2018.00723

Kim, K., Hahm, E., Li, J., Holbrook, L.-M., Sasikumar, P., Stanley, R. G., et al. (2013). Platelet Protein Disulfide Isomerase Is Required for Thrombus Formation but Not for Hemostasis in Mice. Blood 122, 1052-1061. doi:10.1182/blood-2013-03-492504

Law, D. A., Deguzman, F. R., Heiser, P., Ministri-Madrid, K., Killeen, N., and Phillips, D. R. (1999). Integrin Cytoplasmic Tyrosine Motif Is Required for Outside-In $\alpha \operatorname{IIb} \beta 3$ Signalling and Platelet Function. Nature 401, 808-811. doi:10.1038/44599

Lee, C., Park, G. H., Ahn, E. M., Kim, B.-A., Park, C.-I., and Jang, J.-H. (2013). Protective Effect of Codium Fragile against UVB-Induced Pro-inflammatory and Oxidative Damages in HaCaT Cells and BALB/c Mice. Fitoterapia 86, 54-63. doi:10.1016/j.fitote.2013.01.020

Lehnhardt Pires, C., Rodrigues, S., Bristot, D., Gaeta, H., De Oliveira Toyama, D., Lobo Farias, W., et al. (2013). Evaluation of Macroalgae Sulfated Polysaccharides on the Leishmania (L.) Amazonensis Promastigote. Mar. Drugs 11, 934-943. doi:10.3390/md11030934
Li, Z., Delaney, M. K., O’brien, K. A., and Du, X. (2010). Signaling during Platelet Adhesion and Activation. Atvb 30, 2341-2349. doi:10.1161/ atvbaha.110.207522

Maaliki, D., Shaito, A. A., Pintus, G., El-Yazbi, A., and Eid, A. H. (2019). Flavonoids in Hypertension: a Brief Review of the Underlying Mechanisms. Curr. Opin. Pharmacol. 45, 57-65. doi:10.1016/j.coph.2019.04.014

Mcfadyen, J. D., Schaff, M., and Peter, K. (2018). Current and Future Antiplatelet Therapies: Emphasis on Preserving Haemostasis. Nat. Rev. Cardiol. 15, 181-191. doi:10.1038/nrcardio.2017.206

Phillips, D. R., Nannizzi-Alaimo, L., and Prasad, K. S. (2001). Beta3 Tyrosine Phosphorylation in $\alpha \operatorname{IIb} \beta 3$ (Platelet Membrane GP IIb-IIIa) Outside-In Integrin Signaling. Thromb. Haemost. 86, 246-258.

Rubinstein, I., and John Goad, L. (1974). Sterols of the Siphonous marine Alga Codium Fragile. Phytochemistry 13, 481-484. doi:10.1016/s0031-9422(00) 91238-x

Saleh Al-Shehabi, T., Iratni, R., and Eid, A. H. (2016). Anti-atherosclerotic Plants Which Modulate the Phenotype of Vascular Smooth Muscle Cells. Phytomedicine 23, 1068-1081. doi:10.1016/j.phymed.2015.10.016

Shaito, A., Thuan, D. T. B., Phu, H. T., Nguyen, T. H. D., Hasan, H., Halabi, S., et al. (2020). Herbal Medicine for Cardiovascular Diseases: Efficacy, Mechanisms, and Safety. Front. Pharmacol. 11, 422. doi:10.3389/fphar.2020.00422

Shen, B., Zhao, X., O'Brien, K. A., Stojanovic-Terpo, A., Delaney, M. K., Kim, K., et al. (2013). A Directional Switch of Integrin Signalling and a New Antithrombotic Strategy. Nature 503, 131-135. doi:10.1038/nature12613

Suzuki-Inoue, K., Hughes, C. E., Inoue, O., Kaneko, M., Cuyun-Lira, O., Takafuta, T., et al. (2007a). Involvement of Src Kinases and PLC $\gamma 2$ in Clot Retraction. Thromb. Res. 120, 251-258. doi:10.1016/j.thromres.2006.09.003

Suzuki-Inoue, K., Kato, Y., Inoue, O., Kaneko, M. K., Mishima, K., Yatomi, Y., et al. (2007b). Involvement of the Snake Toxin Receptor CLEC-2, in PodoplaninMediated Platelet Activation, by Cancer Cells. J. Biol. Chem. 282, 25993-26001. doi:10.1074/jbc.m702327200

Takagi, J., Petre, B. M., Walz, T., and Springer, T. A. (2002). Global Conformational Rearrangements in Integrin Extracellular Domains in Outside-In and InsideOut Signaling. Cell 110, 599-611. doi:10.1016/s0092-8674(02)00935-2

Trento, F., Cattaneo, F., Pescador, R., Porta, R., and Ferro, L. (2001). Antithrombin Activity of an Algal Polysaccharide. Thromb. Res. 102, 457-465. doi:10.1016/ s0049-3848(01)00264-x

Wang, L., Wang, X., Wu, H., and Liu, R. (2014a). Overview on Biological Activities and Molecular Characteristics of Sulfated Polysaccharides from marine green Algae in Recent Years. Mar. Drugs 12, 4984-5020. doi:10.3390/md12094984

Wang, X., Palasubramaniam, J., Gkanatsas, Y., Hohmann, J. D., Westein, E., Kanojia, R., et al. (2014b). Towards Effective and Safe Thrombolysis and Thromboprophylaxis. Circ. Res. 114, 1083-1093. doi:10.1161/circresaha.114.302514

Watanabe, N., Nakajima, H., Suzuki, H., Oda, A., Matsubara, Y., Moroi, M., et al. (2003). Functional Phenotype of Phosphoinositide 3-kinase P85 -null Platelets Characterized by an Impaired Response to GP VI Stimulation. Blood 102, 541-548. doi:10.1182/blood-2002-11-3327

Wonerow, P., Pearce, A. C., Vaux, D. J., and Watson, S. P. (2003). A Critical Role for Phospholipase $\mathrm{C} \gamma 2$ in aIIb $\beta 3$-mediated Platelet Spreading. J. Biol. Chem. 278, 37520-37529. doi:10.1074/jbc.m305077200

Xu, X. R., Carrim, N., Neves, M. A., Mckeown, T., Stratton, T. W., Coelho, R. M., et al. (2016). Platelets and Platelet Adhesion Molecules: Novel Mechanisms of Thrombosis and Anti-thrombotic Therapies. Thromb. J. 14, 29. doi:10.1186/ s12959-016-0100-6

Conflict of Interest: The authors declare that the research was conducted in the absence of any commercial or financial relationships that could be construed as a potential conflict of interest.

Copyright $\odot 2021 \mathrm{Kim}, \mathrm{Kim}$ and Kim. This is an open-access article distributed under the terms of the Creative Commons Attribution License (CC BY). The use, distribution or reproduction in other forums is permitted, provided the original author(s) and the copyright owner(s) are credited and that the original publication in this journal is cited, in accordance with accepted academic practice. No use, distribution or reproduction is permitted which does not comply with these terms. 